\title{
Early Detection of the Universal Bacterial and Fungal DNA in Late Neonatal Sepsis
}

\author{
Ma. Esterlita Villanueva Uy ${ }^{1,2}$ Carmen R. Briones ${ }^{1}$ and Herbert G. Uy ${ }^{1}$ \\ ${ }^{1}$ Department of Pediatrics, College of Medicine and Philippine General Hospital, University of the Philippines Manila \\ 2Institute of Child Health and Human Development, National Institutes of Health, University of the Philippines Manila
}

\begin{abstract}
Background. Sepsis is the leading cause of neonatal morbidity and mortality in the Neonatal Intensive Care Units of developing countries. Early detection of septicemia will lead to early initiation as well as judicious use of antibiotics in the hope of decreasing neonatal mortality.
\end{abstract}

Objective. To determine the sensitivity and specificity of Polymerase Chain Reaction (PCR) using universal DNA sequences for bacterial and for Candidal species in blood cultures of neonates more than three days old.

Method. Blood samples were drawn for both culture and PCR among 61 newborn infants suspected of sepsis. DNA sequences universal for bacterial (16s RNA) and Candidal (ITS) species were amplified.

Results. Forty six (75\%) neonates had a positive blood culture. PCR amplifying the bacterial DNA had a sensitivity of 79\% (95\% Cl: 60-92), specificity of $100 \%(95 \%$ Cl: $88-100)$; Positive Predictive Value (PPV), $100 \%$, and Negative Predictive Value, $84 \%$. All false negative PCR results $(n=6)$ had Pseudomonas culture growths. For Candidal pathogens, PCR had a sensitivity of $95 \%$ (95\% Cl: $76-100)$, specificity of $95 \%$ (95\% Cl: $83-99)$, PPV of $91 \%$, and NPV of $97 \%$.

Conclusions. Although some estimates lack precision, PCR is a good screening tool for neonatal sepsis with its high specificity and sensitivity, NPV, and PPV for both bacterial and Candidal species. Modification of DNA extraction technique may further improve the sensitivity of $P C R$, especially for Pseudomonas sepsis.

Key Words: newborn, sepsis, bacteremia, candidemia, $P C R$

\section{Introduction}

In 2010, majority (64\%) of the 7.6 million deaths in children under 5 years of age has an infectious etiology with the neonatal population (40.3\%) accounting for almost half

Corresponding author: Ma. Esterlita Villanueva Uy, MD

Department of Pediatrics

Philippine General Hospital

University of the Philippines Manila

Taft Avenue, Ermita, Manila 1000 Philippines

Telephone: +6325240892

Email: herb_tita@yahoo.com of these deaths. ${ }^{1}$ Sepsis is the third leading cause of neonatal death worldwide. In the Neonatal Intensive Care Units in developing countries, sepsis is the leading cause of neonatal morbidity and mortality.

Early diagnosis of neonatal sepsis is difficult due to its protean manifestations. Clinical signs are non-specific and may often be secondary to non-infectious causes like metabolic or thermoregulation problems. Although the incidence of sepsis is low in developed countries, it has considerably high morbidity and mortality. As such, the Center for Communicable Diseases' (CDC) recommendation is to start all high-risk infants on antibiotics pending culture results. Most non-septic infants receive three to seven days of antibiotics even after a negative blood culture. Such strategy clearly leads to longer hospital stay and higher hospital bills for non-septic infants, as well as emergence of resistant strains in the nursery. ${ }^{2}$

In a report from the United States National Institutes of Child Health and Human Development (US-NICHHD) Neonatal Research Network, early onset sepsis is included in the differential diagnosis of most preterm infants. Although neonatal sepsis is uncommon in developed countries, mortality due to early onset sepsis is as high as $26 \%{ }^{3}$ Antibiotic therapy for suspected sepsis is frequently initiated at birth. Almost half of the infants in this cohort were considered to have clinical sepsis and continued to receive antibiotics for five or more days, despite a negative blood culture result in $98 \%$ of cases. These findings underscore the difficulty of ruling out sepsis in immature symptomatic infants. The authors believe that improved strategies are needed to enable the clinician to distinguish between the infected and the uninfected neonates with symptoms and to target continued antibiotic therapy to those who are truly infected.

Early recognition and aggressive resuscitation of neonatal sepsis can lead to a nine-fold increase in survival of these infants. A lot of laboratory tools and scoring systems have been studied but all of them showed low sensitivities and specificities. Inter-physician agreement on clinical assessment of sepsis in critically ill children has also been found to be unacceptably low. There is a need for a laboratory tool, which has high sensitivity, high specificity, and fast turnaround time. ${ }^{4}$ This may result in rapid 
decongestion of the nurseries by earlier discharges and appropriate antibiotic use. The need for a rapid and reliable method of identifying a pathogen is of paramount importance since this will dramatically reduce length of hospitalization, medical cost, and exposure to nosocomial infection.

Common laboratory tests presently employed have low sensitivities and specificities. Abnormal white cell count has a specificity of $41 \%$. Other ancillary tests like C-reactive protein, ESR and others are also non-specific for the detection of sepsis. Blood culture, which is considered as a gold standard, has also been questioned due to low yields (80\%) among neonates. ${ }^{5}$

Polymerase Chain Reaction (PCR) is a promising tool in the early detection of sepsis. Amplification of DNA sequences by PCR has been found to be highly sensitive and specific and has fast turnaround time compared to blood cultures. However, DNA sequences amplified by PCR in the field of microbiology usually involve DNA segments specific for a microorganism. Fortunately, there are highly conserved DNA sequences which are universal and specific to all prokaryotes and absent in eukaryotes. A very useful and highly conserved DNA sequence is that which codes for the 16s ribosomal RNA. Detection of such a DNA sequence in any specimen will indicate the presence of a prokaryote (bacteria). A study by $\mathrm{McCabe}^{6}$ utilized the 16s rRNA as a molecular triage for sepsis. He found high sensitivity and specificity of PCR for 16s RNA compared to bacterial cell cultures. Studies by Laforgia ${ }^{4}$ and Jordan ${ }^{7}$ have shown high specificity and sensitivity of PCR using clinical blood specimens from neonates suspected with early onset sepsis. Due to a lower incidence of bacteremia in early onset sepsis, positive results were low in both studies.

There are also highly conserved DNA sequences specific for Candida species. An example is the internal transcribing spaces also coding for the $16 \mathrm{~s}$ RNA. ${ }^{8}$ Fujita ${ }^{9}$ showed excellent sensitivities and specificities on the amplification of a universal sequence for Candida in the newborn infants.

Rapid detection of late onset sepsis is also important since more than $25 \%$ of preterm infants have one or more episodes of blood culture proven sepsis. Moreover, neonates in whom late-onset sepsis develop are significantly more likely to die than those who are not infected (17\% vs. $7 \%$; $\mathrm{p}<0.0001) .{ }^{10}$ In the PGH NICU, ${ }^{11}$ the most common pathogens are the gram-negative bacilli and Candida. As such, detection not only of the presence or absence of bacteria but also that of Candida will not only help clinicians decide whether to initiate antibiotics or not in symptomatic infants, but also will guide them on type of antibiotic to be started on infants who are truly infected.

This present study investigated the diagnostic properties of the amplified universal DNA sequences of bacterial and Candida in detecting late onset sepsis among neonates against blood culture as the gold standard.

\section{Methods}

\section{Patient recruitment}

Newborn infants were recruited from 2001 to 2003 in the study according to the following criteria:

\section{Inclusion criteria}

1. Infants greater than 3 days old suspected of lateonset sepsis in whom a septic work up which includes a blood culture has been requested by the attending physician

2. Born at the Philippine General Hospital-NICU

3. Parents or legal guardians gave informed consent

\section{Exclusion criteria}

Sick newborn infants in whom additional volume of blood to be extracted is deemed detrimental by the attending physician.

\section{Sample Size}

With a confidence level set at 95\% ( $\alpha=0.05), 35$ neonates were needed to estimate the sensitivity (assumed to be $90 \%$ ) at $5 \%$ precision, Same number of neonates are needed to estimate the sensitivity (assumed to be $90 \%$ ) at $5 \%$ precision. Assuming $30 \%$ prevalence of sepsis, ${ }^{10} 117$ patients are needed.

\section{DNA Extraction}

From each neonate, a single blood draw for culture (1 $\mathrm{ml})$ and PCR $(0.5 \mathrm{ml})$ was done using strict asepsis technique. Blood was stored in $-80^{\circ} \mathrm{C}$ freezer prior to DNA extraction. DNA was then extracted from all patient blood specimens using a commercially available kit, QIAamp DNA Mini Blood kit, following procedure in the manual.

\section{Universal Bacterial DNA Amplification}

For identification of bacterial DNA strand, the PCR mixture consisted of the following: 10X PCR Buffer 5 ul, 10mM dNTP 1 ul, $50 \mathrm{mM} \mathrm{MgSO} 42$ ul, primers (10 uM) 1 ul (0.5 ul each), Tag Polymerase ( $2.5 \mathrm{U}$ ) $0.5 \mathrm{ul}$, specimen $10 \mathrm{ul}$, and distilled water $0.5 \mathrm{ul}$. Total volume of the mixture was 90 ul. The primers used were DG74 5'AGGAGGTGATCCAACCGCA-3' and RWO1 5'AACTGGAGGAAGGTGGGGAT-3'

\section{Universal Candidal DNA Amplification}

Still using the QIAamp kit, the PCR mixture used for detecting the presence of Candidemia was consisted of the following: 10X PCR Buffer 5ul, $10 \mathrm{mM}$ dNTP $1 \mathrm{ul}, \mathrm{MgCl} 2$

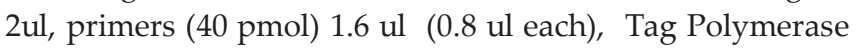
$0.5 \mathrm{ul}$, specimen $2.0 \mathrm{ul}$, and distilled water 37.9 ul. Total volume for this second mixture is $50.0 \mathrm{ul}$. The primers used were ITS3 5'-GCATCGATGAAGGCAGC-3' and ITS4 5'TCCTCCGCTTATTGATATGC-3'. 
Samples were placed in the Bio-Rad Gene cycler. The PCR consisted of 28 cycles with the following settings: incubation: $95^{\circ} \mathrm{C}, 10$ minutes; denaturation phase of $95^{\circ} \mathrm{C}$ at 1 minute; annealing phase of $60^{\circ} \mathrm{C}$ at 2 minutes; extension phase of $72{ }^{\circ} \mathrm{C}$ at 1 minute; and terminal extension of $72{ }^{\circ} \mathrm{C}$ at 10 minutes. Positive controls used were E. coli for the bacterial PCR and Candida albicans for the Candidal PCR. Water was utilized as the negative control.

Gel electrophoresis with $1.5 \%$ agarose gel was conducted with 1XTBE Buffer (0.1 M Tris, $0.09 \mathrm{M}$ boric acid, $1 \mathrm{mM}$ EDTA). Ten ul of PCR master mix were analyzed in the electrophoresis at 57 volts for 2 hours for the detection of the presence of bacterial and fungal organisms. A $100 \mathrm{bp}$ DNA ladder (Invitrogen) was ran concurrently with amplicons for sizing of the bands. Staining was then employed with a solution of ethidium bromide with a final concentration of $15 \mathrm{mcg} / \mathrm{ml}$ (20 ul ethidium bromide combined with $200 \mathrm{ml}$ distilled water) was prepared. Gels were stained for 20 minutes and then photographed. Basing from Jordan's study, the bands between 300 and 400 corresponded to presence of bacteria. In the present study, bands were measured at $380 \mathrm{bp}$. On the other hand, for Candidemia, sizes of 233 to 432 were utilized as patterned from Fujita's research which used ITS3 and ITS4 primers. Bands were read separately by a microbiologist and a medical doctor.

\section{Methods of Data Analysis}

The sensitivity and specificity were estimated at $95 \%$ confidence level. PPV and NPV were also reported.

\section{Results}

Despite methods to improve recruitment, only 61 newborn infants were included in this study. Forty-six had positive blood culture while the remaining 15 samples were negative for both bacteria and Candida species. Of the 46 positive findings, 25 had bacterial pathogens, 17 had Candida, and 4 had both bacteria and Candidal growth (Table 1).

Table 1. Frequency Distribution of culture results from blood samples $(n=61)$.

\begin{tabular}{lcc}
\hline \multicolumn{1}{c}{ CULTURE RESULTS } & NUMBER & PERCENTAGE (\%) \\
\hline (+) Bacteremia & 25 & 40.98 \\
(+) Candidemia & 17 & 27.87 \\
(+) Both Bacteremia and & 4 & 6.56 \\
Candidemia & & \\
(-) Culture & 15 & 24.59 \\
TOTAL & $\mathbf{6 1}$ & $\mathbf{1 0 0}$ \\
\hline
\end{tabular}

For bacterial pathogens (Figure 1), PCR, compared with blood culture, had a sensitivity of $79 \%$ (95\% CI: 60-92), specificity of $100 \%$ (88-100), PPV of $100 \%$, and NPV of $84 \%$. All false negative PCR had culture growths of Pseudomonas (Table 2).

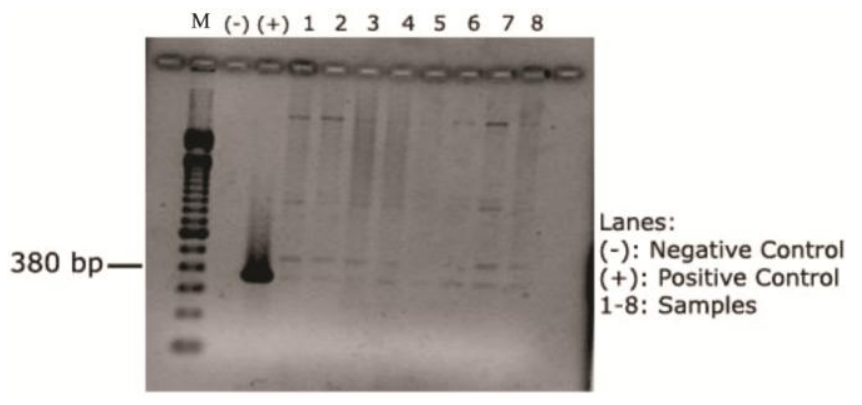

Figure 1. Gel electrophoresis of PCR products after amplification of the $16 \mathrm{~s}$ rDNA for bacterial pathogens.

Table 2. Comparison of Blood Culture and PCR results for bacteremia $(\mathrm{n}=61)$.

\begin{tabular}{llccc}
\hline & \multicolumn{2}{c}{ BLOOD CULTURE } & \\
\cline { 3 - 4 } & & $\begin{array}{c}(+) \\
\text { Bacteremia }\end{array}$ & $\begin{array}{c}(-) \\
\text { BOteremia }\end{array}$ & \\
\hline & (+) Bacterial DNA & 23 & 0 & $\mathbf{2 3}$ \\
PCR & $(-)$ Bacterial DNA & 6 & 32 & 38 \\
TOTAL & $\mathbf{2 9}$ & $\mathbf{3 2}$ & $\mathbf{6 1}$ \\
\hline \multicolumn{2}{l}{} & & & \\
\hline Sensitivity: & 0.79 & PPV: & 1.0 & \\
Specificity: & 1.0 & NPV: & 0.84 & \\
\hline
\end{tabular}

For Candidal pathogens (Figure 2), PCR had a sensitivity of $95 \%$ (95\% CI: 76-100), specificity of $95 \%$ (95\% CI: 83-99), PPV of 91\%, and NPV of $97 \%$ (Table 3).

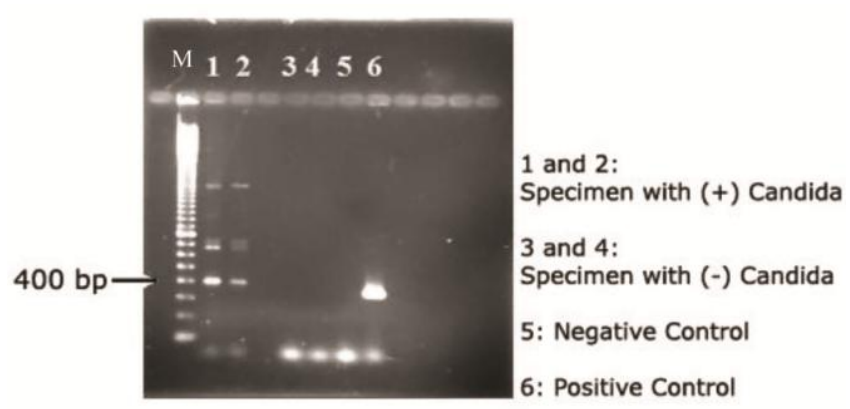

Figure 2. Gel electrophoresis of PCR products after amplification of the ITS sequence for Candidal pathogens.

Table 3. Comparison of Blood Culture and PCR results for Candidemia $(\mathrm{n}=61)$.

\begin{tabular}{|c|c|c|c|c|c|}
\hline & & & \multicolumn{2}{|c|}{ BLOOD CULTURE } & \multirow[b]{2}{*}{ TOTAL } \\
\hline & & & $\begin{array}{c}(+) \\
\text { Candidemia } \\
\end{array}$ & $\begin{array}{c}(-) \\
\text { Candidemia } \\
\end{array}$ & \\
\hline & \multicolumn{2}{|c|}{ (+) Candidal DNA } & 20 & 2 & 22 \\
\hline PCR & \multicolumn{2}{|c|}{ (-) Candidal DNA } & 1 & 38 & 39 \\
\hline \multicolumn{3}{|c|}{ TOTAL } & 21 & 40 & 61 \\
\hline Sensi & vity: & 0.95 & PPV: & 0.91 & \\
\hline Speci & city: & 0.95 & NPV: & 0.97 & \\
\hline
\end{tabular}




\section{Discussion}

Previous reports have studied either bacterial or Candidal sequences but never both. Amplifications of universal sequence of both bacterial and Candidal pathogens were done so that the two most common pathogens in the NICU were screened. In this study although some estimates lack precision, the sensitivity and specificity in the detection of the Candidal sequence were both high. In bacterial sequence amplification, there was a high specificity but only moderate sensitivity. It was found out that all false negative blood specimens grew Pseudomonas bacteria. The problem with non-amplification of Pseudomonas may be due to a more resistant cell membrane that is harder to lyze using the standard PCR process. Modification of the DNA extraction step described in the earlier section on Methods led to successful amplification of Pseudomonas cultures.

A number of studies have amplified either the universal bacterial DNA or the candidal DNA, in this study both of the DNA's were amplified. As such, it is truly relevant to clinical practice especially in late onset or nosocomial sepsis in which both bacterial and Candidal infections are common. Furthermore, PCR mixtures for both amplification of bacteria and Candida were amplified using identical PCR cycles unlike in previous studies in which PCR cycles used differed. Using identical PCR cycles for both bacteria and Candida will enable running specimens simultaneously further reducing turnaround time for results.

The bacterial PCR mixtures and cycles for this study were patterned after Jordan's study ${ }^{7}$ on application of PCR for early onset sepsis. Sensitivity and specificity were likewise high. However, since he was dealing with early onset sepsis, he did not encounter the problem with Pseudomonas which is an uncommon pathogen in early onset sepsis. Dealing with late onset sepsis gave the opportunity to be acquainted with the difficulty of extracting DNA from Pseudomonas species leading to modification of the protocol to be able to also successfully amplify Pseudomonas spp. In this study, modification of the DNA extraction by the addition of boiling for 10 minutes prior to the recommended QIAamp protocol led to excellent amplification of desired sequences from Pseudomonas culture plates (not patient specimens).

In a similar study by $\mathrm{Wu}^{12}$ in 2007 , detection of the $16 \mathrm{~S}$ rRNA in bacterial cultures by real time PCR has a high sensitivity and specificity. The proportion of positive PCR results by real-time PCR assay was $5.18 \%$ which is higher than the positive blood culture $[2.41 \%(20 / 830)(P<0.01)]$. In this study, the higher proportion of positive PCR and blood culture may be due to the focus on late onset sepsis which has a higher positive yield. Late onset sepsis mainly covers hospital acquired infections which is 3-20 times higher in developing countries compared with industrialized ones. ${ }^{13}$

The high sensitivity and specificity of Candidal PCR in this study is comparable with that of Tirodker ${ }^{8}$ who had a similar study. However, his study had amplified a different DNA sequence and had a higher false negativity rate than the present study.

The time required to complete the bacterial PCR assay was roughly 6.5 hours. This includes 1.5 hours for sample preparation, 3.0 hours for the DNA amplification, and 2.0 hours for sample detection for gel electrophoresis. On the other hand, blood culture results were obtained on the average of 3.5 days. During this waiting time for blood culture results to be obtained, cost of antibiotics, hospital stay and parental loss of income are significant. Furthermore, a blood-culture negative infant would receive more doses of antibiotic treatment translating to increased hospital expenses and leading to increased probability of antibiotic resistance on the part of the neonate. The fast turnaround time PCR may allow cessation of antibiotic therapy at the earliest possible time in high risk patients who do not have sepsis. This will lead to a more judicious use of antibiotics in the nursery, in the hope of reducing antibiotic resistance. Moreover, cost of antibiotic therapy will also be reduced in these infants.

\section{Conclusion and Recommendation}

PCR Amplified bacterial and Candidal sequences can be a potential test in the detection of neonatal sepsis. The specificity is high and although low in precision, sensitivity may be considered good. These diagnostic properties may be made better by using an improved extraction procedure to amplify Pseudomonas. Also, short turnaround time (6.5 hours) can lead to early cessation of antibiotic therapy and cut down cost of treatment.

We recommend a larger study to improve the precision of the estimates followed by possible institution of a neonatal screening by PCR in all high risk infants suspected of sepsis in the NICU in the hope of decreasing hospital stay, cost, and emergence of resistant strains.

This study received a grant (NIH 2001-117) from the National Institutes of Health, University of the Philippines Manila.

\section{Acknowledgments}

We would like to thank Dr. Jason Alacapa for helping us write the manuscript as well as Drs. Edgardo Ortiz and Alexander Tuazon for all their support.

\section{References}

1. Liu L, Johnson HL, Cousens S, et al. Global, regional, and national causes of child mortality: an updated systematic analysis for 2010 with time trends since 2000. Lancet. 2012; 379(9832):2151-61.

2. Scrag S, Phil N, Schucha A. Prevention of Neonatal Sepsis. Clinics in Perinatology. 2005:32: 501-615.

3. Stoll BJ, Gordon T, Korones SB, et al. Early-onset sepsis in very low birth weight neonates: a report from the National Institute of Child Health and Human Development Neonatal Research Network. J Pediatr. 1996; 129(1):72-80. 
4. Laforgia N, Coppola B, Carbone R, Grassi A, Mautone A, Iolascon A. Rapid detection of neonatal sepsis using polymerase chain reaction. Acta Pediatr. 1997; 86(10):1097-9.

5. Malik A, Hui CP, Pennie RA, Kirpalani H. Beyond the complete blood cell count and C-reactive protein: a systematic review of modern diagnostic tests for neonatal sepsis. Arch Pediatr Adolesc Med. 2003; 157(6):511-6.

6. McCabe KM, Khan G, Zhang YH, Mason EO, McCabe ER. Amplification of bacterial DNA using highly conserved sequences: automated analysis and potential for molecular triage of sepsis. Pediatrics. 1995; 95(2):165-9.

7. Jordan JA, Durso MB. Comparison of $16 \mathrm{~S}$ rRNA gene PCR and BACTEC 9240 for detection of neonatal bacteremia. J Clin Microbiol. 2000; 38(7):2574-8.

8. Tirodker UH, Nataro JP, Smith S, LasCasas L, Fairchild KD. Detection of fungemia by polymerase chain reaction in critically ill neonates and children. J Perinatol. 2003; 23(2):117-22.

9. Fujita SI, Senda Y, Nakaguchi S, Hashimoto T. Multiplex PCR using internal transcribed spacer 1 and 2 regions for rapid detection and identification of yeast strains. J Clin Microbiol. 2001;39(10):3617-22

10. Stoll BJ, Gordon T, Korones SB, et al. Late-onset sepsis in very low birth weight neonates: a report from the National Institute of Child Health and Human Development Neonatal Research Network. J Pediatr. 1996; 129(1), 63-71.

11. University of the Philippines - Philippine General Hospital. Neonatal Intensive Care Unit (NICU) Annual Statistics, 2011.

12. Wu YD, Shang SQ, Li JP, et al. A broad-range $16 \mathrm{~S}$ rRNA gene real-time PCR assay for the diagnosis of neonatal septicemia. [Article in Chinese]. Zhonghua Er Ke Za Zhi. 2007; 45(6):446-9.

13. Zaidi AK, Huskins WC, Thaver D, Bhutta ZA, Abbas Z, Goldmann DA. Hospital-acquired neonatal infections in developing countries. Lancet. 2005; 365(9465):1175-88

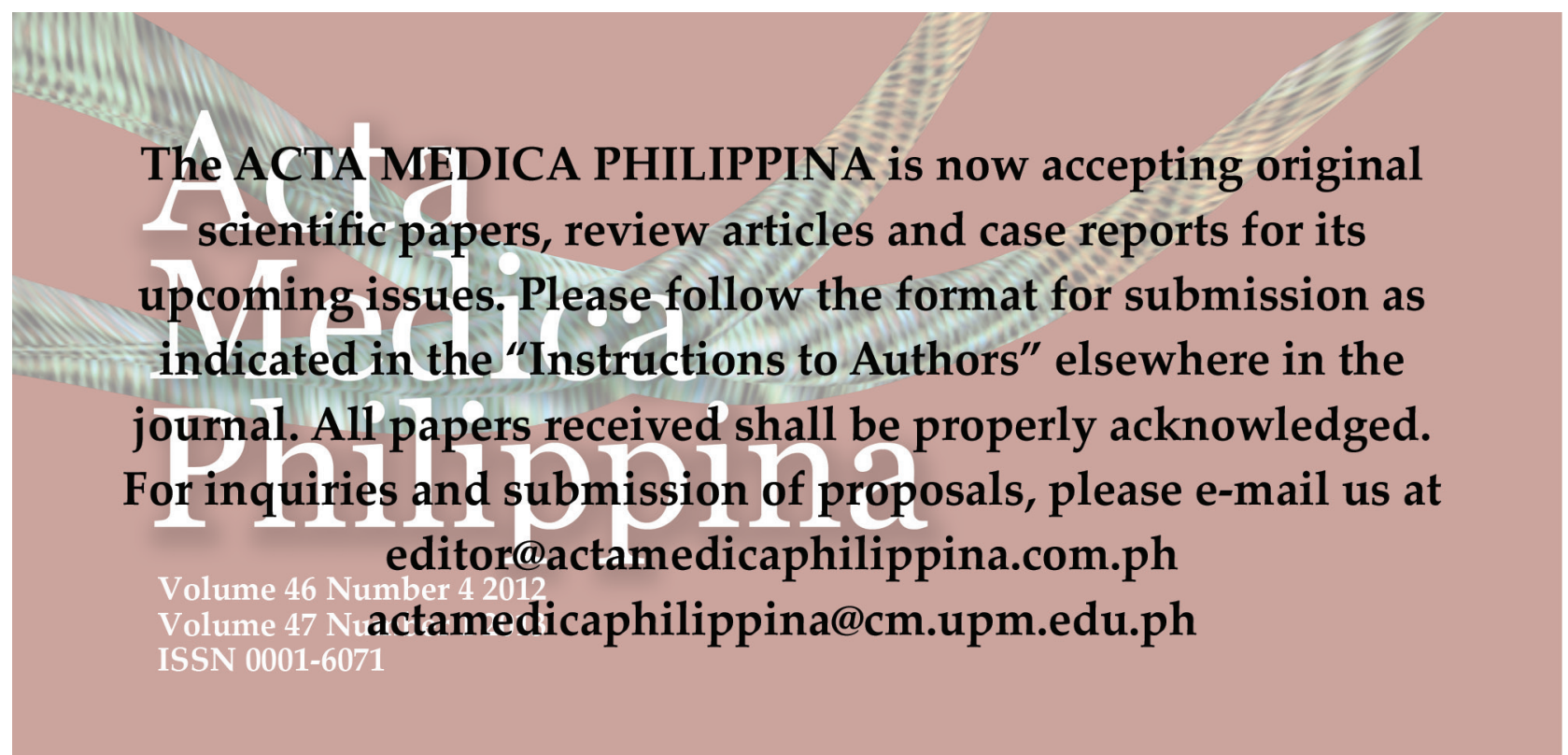

